\title{
Identifying C-N Heterodiamonds with SEM, TEM and Raman Scattering
}

\author{
L. C. Ming, ${ }^{*}$ P. V. Zinin*, M. H. Manghnani,* T. Carvalho*, S.M. Hong**, Y. Xie*** \\ *School of Ocean and Earth Science and Technology, University of Hawaii, Honolulu, USA \\ ** High Pressure Laboratory, Southwest Jiaotung University, Chengdu, Sichuan, China \\ *** Structure Research Laboratory and Department of Chemistry, University of Science and \\ Technology of China, Hefei, Anhui, China
}

The prediction by Liu and Cohen [1] of the existence of a $\beta-\mathrm{C}_{3} \mathrm{~N}_{4}$ phase with a bulk modulus and hardness similar to diamond has led to an enormous effort to synthesize this material. However, search for new superhard materials in the last decade indicates that the synthesis of phases with hardness exceeding that of diamond is unlikely. Now, it seems worthwhile to refocus the search for new superhard phases on synthesis of materials more useful than diamond, rather than those harder than diamond. Such phases are predicted to be inside the B-C-N system. Superhard diamond-like phases from the B-C-N triangle are highly desirable, as they might combine the best properties of the elemental or binary compounds of the system, such as a diamond and a cubic boron nitride (cBN), and are expected to be thermally and chemically more stable than diamond, and harder than $\mathrm{cBN}$. The new phases can be obtained under high $(>20 \mathrm{GPa})$ pressures and temperatures $(>2000 \mathrm{~K})$. In this report we show that electron microscopy plays an important role in the identifying the new phase.

A Mao-Bell type diamond anvil cell (DAC) together with the laser-heating system was used to synthesis diamond-like phase from the graphitic phase. The laser-heating system with a Nd-doped YAG laser (wavelength $=1064 \mathrm{~nm}$ and a max. power of $9 \mathrm{~W}$ at TEM $_{00}$ mode) is able to heat samples up to $3000 \mathrm{~K}$. A laser with a heated spot of 10-20 $\mu \mathrm{m}$ scanned the central area of both samples (Fig. 1a). After heating, sample was quenched to room temperature and gradually decompressed to 1 atmospheric pressure (Fig. 1b). The recovered samples were examined using synchrotron-based X-ray diffraction, Raman spectroscopy for phase identification, and ED-SEM and EELS for composition determination. Results thus obtained will be presented and the probably high pressure phase will be discussed

Graphite-like $\mathrm{C}_{3} \mathrm{~N}_{4}\left(g-\mathrm{C}_{3} \mathrm{~N}_{4}\right)$ phase was used to synthesize new phases. Two samples were heated in the DAC to $1530 \mathrm{~K}$ at $48 \mathrm{GPa}$ and to $2000 \mathrm{~K}$ at $33 \mathrm{GPa}$, respectively. After quenched and decompressed to the atmospheric pressure from high-pressure, the recovered sample has been studied by scanning electron microscope. Figures $2 \mathrm{a}$ is the SEM image of the $\mathrm{C}_{3} \mathrm{~N}_{4}$ sample. The resolution of energydispersive detector of the JEOL JSM-5900 SEM was sufficient for quantitative chemical analysis of $\mathrm{C}_{3} \mathrm{~N}_{4}$ compounds. EDS measurements of the sample heated to $1500 \mathrm{~K}$ at $48 \mathrm{GPa}$ conducted at five point shown in Fig. 2 a provide the following value of the $\mathrm{C} / \mathrm{N}$ ratio as $0.92 \pm 0.16$. Similar ratio was obtained for a diamond-like sample obtained under $2000 \mathrm{~K}$ and $33 \mathrm{GPa}$. The $\mathrm{C} / \mathrm{N}$ composition was found to be homogeneous over the surface of the sample. Fig. $2 \mathrm{~b}$ is the TEM image of the graphitic $\mathrm{C}_{3} \mathrm{~N}_{4}$. It is interesting to note that that $\mathrm{C} / \mathrm{N}$ ration in $\mathrm{g}-\mathrm{C}_{3} \mathrm{~N}_{4}$ phase was $0.65+/-0.07$. EELS measurements (Fig. 3) are in a good agreement with into ED-SEM measurements. The possible reason of the change of the $\mathrm{N} / \mathrm{C}$ ratio during phase transformation is discussed in the report.

\section{References}

[1] A. Y. Liu and M. L. Cohen, Science, vol. 245, pp. 841-842, 1989.

[2] This work was supported by the National Science Foundation, Grant No. DMR-0102215. 

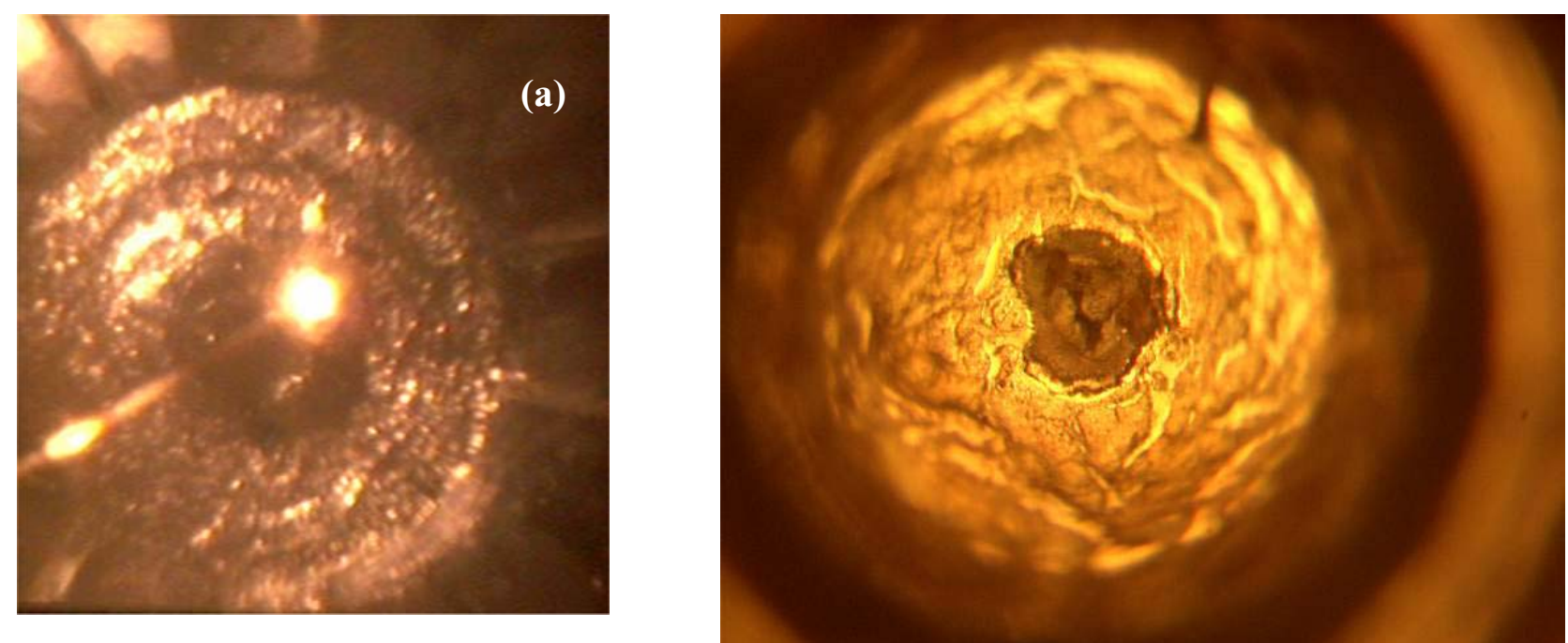

Fig.1. Optical images of the $\mathrm{C}_{3} \mathrm{~N}_{4}$ at high pressure in the cell: (a) during the laser-heating, where the bright spot is the heating spot, (b) the the recovered post-lasered sample of $\mathrm{C}_{3} \mathrm{~N}_{4}$ from high pressure.
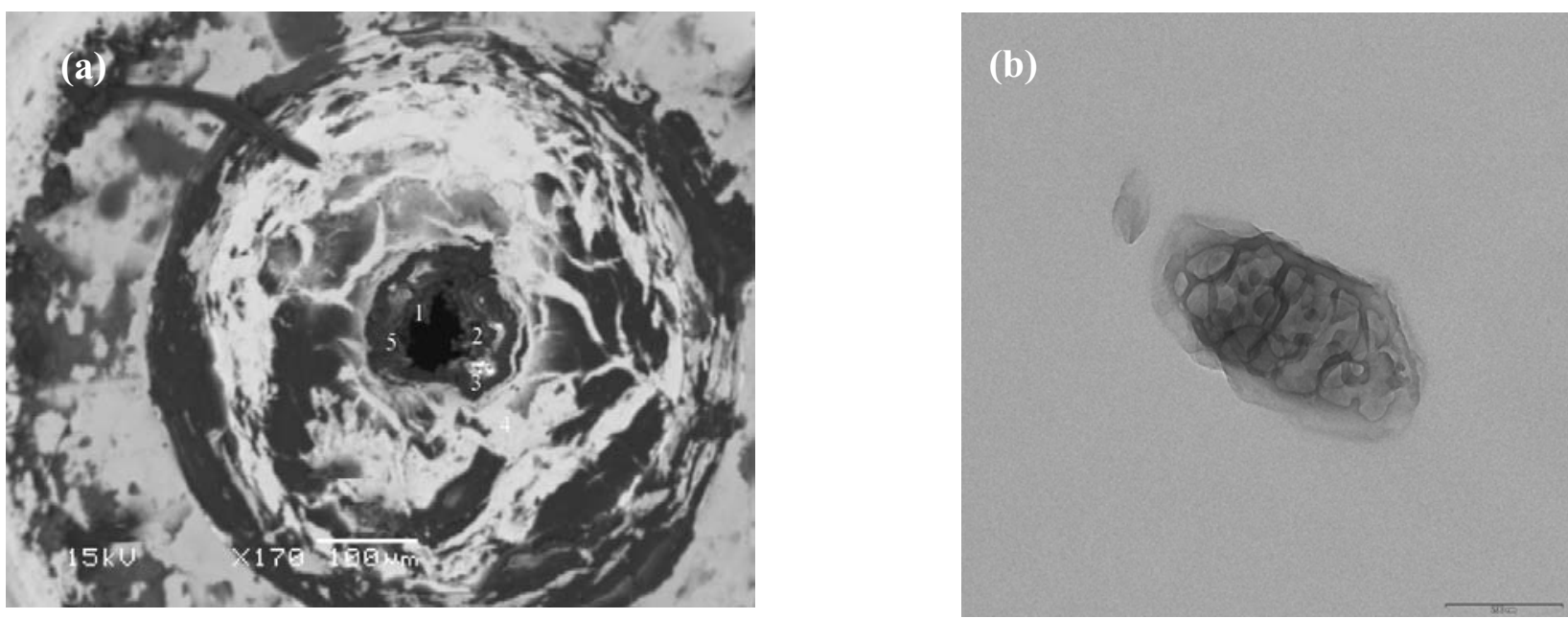

Fig.2. (a) SEM image of the recovered $\mathrm{C}_{3} \mathrm{~N}_{4}$ sample. Marker is $50 \mu \mathrm{m}$. (b) TEM image of the starting graphitic- $\mathrm{C}_{3} \mathrm{~N}_{4}$ phase. Marker is $20 \mathrm{~nm}$
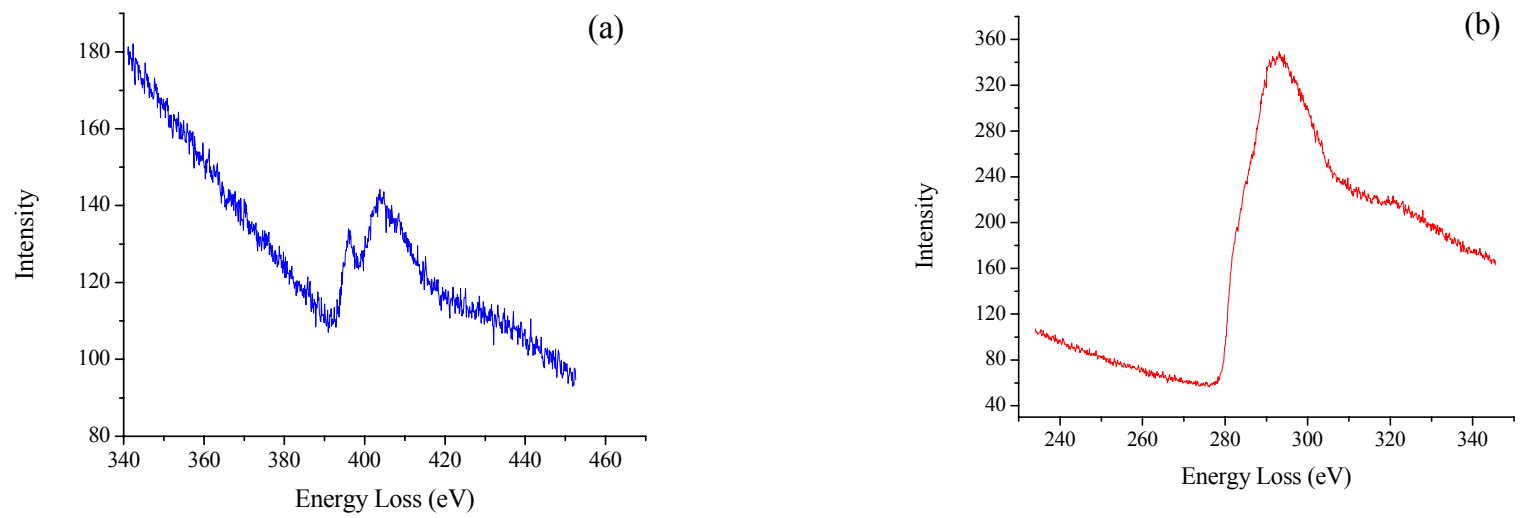

Fig. 4. EELS spectra of nitrogen (a) and carbon (b) in the graphitic $\mathrm{C}_{3} \mathrm{~N}_{4}$. 